\title{
Filosofía de la liberación en Colombia
}

Lidia CANo OBREgón

Coautora

En el desarrollo del pensamiento filosófico de Colombia, respecto al resto de los países latinoamericanos, se aprecia algo similar a la situación que confrontó España en relación con Europa en los momentos de la entrada de la modernidad, cuando las fuerzas retardatarias de la Iglesia obstaculizaron la penetración de las ideas renovadoras.

Si bien desde finales del siglo XVII, gracias al incremento de las relaciones mercantiles, hubo cierto auge económico que repercutió en todas las esferas de la vida cultural de ese país y en especial en su vida filosófica, nunca llegaría a alcanzar por entonces la fuerza que fue tomando esta actividad intelectual (Nieto, 1983b, p. 15) ${ }^{116}$ en otros pueblos latinoamericanos.

116 “Así los principios en que se apoyó la colonización en lo que hoy es Colombia establecían: en industria y comercio, el monopolio, el privilegio y el provecho exclusivo de la madre patria; en política, la centralización absoluta y el predominio de la raza conquistadora; en ciencias y arte, la ignorancia; en filosofía, la abyección de espíritu; y en religión, la intolerancia y el fanatismo...". Nieto Arteta y Luis. E. Economía y cultura en la historia de Colombia, El Ancora Editoras, Bogotá, 1983. p.15. 
La escolástica fue la filosofía que durante un tiempo, mucho más prolongado que en otras partes, se impuso y limitó de algún modo las potencialidades del pensamiento ilustrado. El hecho de que los liberales colombianos de finales del siglo XIx (Jaramillo, 1964) se quejaran de lo que llamaban "nuestra tardía edad media" (Zabalza, 1988, p.107) constituye una muestra de la repercusión que aún mantenía el espíritu de la contrarreforma en Colombia.

Una devalorización del oficio de la razón y una mayor preocupación por los asuntos de la fe motivó que la actividad filosófica quedase enclaustrada en monasterios y universidades religiosas. Aun así, el pensamiento ilustrado tuvo en Colombia brillantes representantes como José Félix de Restrepo, los sabios Francisco José de Caldas y José Celestino Mutis y el político Antonio Nariño, entre otros (Marquínez, 1982, p. 14). La naciente burguesía colombiana impulsó la actividad de estos ilustrados, en tanto este movimiento contribuyó a la preparación del proceso independentista que se avecinaba.

La ilustración neogranadina constituyó un movimiento cultural de gran trascendencia no solo para la vida filosófica del país, sino también para la fermentación de las ideas reformistas y revolucionarias que llegaron a alcanzar una de sus máximas expresiones en el movimiento comunero de mediados del siglo xviII.

En tanto el positivismo y el materialismo científico natural ganaban adeptos de forma creciente en la mayoría de los países latinoamericanos, desempeñando una función muy progresista para su época (Guadarrama, Rivero, Rojas, Rensoli, Fleites, 1988, pp. 26-26), ${ }^{117}$ en Colombia el proceso de recepción de estas corrientes quedaría mutilado a raíz del Concordato firmado entre la Iglesia y el Estado que no permitió que proliferaran más

117 "El positivismo fue la filosofía predominante en el ámbito latinoamericano desde mediados del siglo xIx hasta las primeras décadas del siglo xx Esta filosofía en este contexto expresó los intereses burgueses de carácter progresista, que en dicho período pretendían sustituir las caducas relaciones precapitalistas de producción y estimular el desarrollo industrial como condición necesaria para alcanzar la verdadera independencia de los pueblos latinoamericanos, ideal este que fue frustrado por la penetración imperialista'. Rivero, D. M. Rojas; Lourdes Rensoli; Maricela Fleites; y Pablo Guadarrama; "El positivismo y el materialismo científico natural en Latinoamérica", en La filosofía en México, Siglo xx, Universidad Autónoma de Tlaxcala, Tlaxcala 1988. pp. 25-26. 
estas corrientes y descollaran otras personalidades de gran talla (Sciacca, 1959, p. 129) como en otras partes.

Desde el principio del siglo xx el catolicismo pretendía mantener su predominio en todos los órdenes de la vida cultural colombiana y, con ese fin, la labor revitalizadora del tomismo desarrollada por Rafael María Carrasquilla (Tovar, 1982, pp. 297-341) impregnaría de manera significativa al ambiente filosófico del país.

Con el advenimiento de la república neoliberal en 1930 y el planteamiento de una reforma universitaria aparecieron nuevas influencias filosóficas. En particular las ideas de Ortega y Gasset (Naranjo, 1988, p. 132). ${ }^{118}$

Max Scheler (Carrillo, 1986, pp. 27-28) ${ }^{119}$ y Hans Kelsen se hicieron sentir. Uno de los representantes principales de ese movimiento renovador fue Abel Naranjo. Esta fue la época en que el marxismo incrementa también considerablemente su recepción con figuras como Luis Eduardo Nieto Arteta (Cataño, 1983, pp. 171-196) y otros intelectuales y personalidades de la vida política colombiana (Jaramillo Vélez, 1988, pp. 205-248) que trascenderían por su actividad académica en las siguientes décadas como Antonio García Nosa, (Villamizar, 2007) ${ }^{120}$ entre otros.

118 "Hacia ese año (1930), empezó a circular la Revista de Occidente que dirigía, en Madrid, José Ortega y Gasset. Los jóvenes que por esos años cursábamos en la Universidad, acudíamos a las librerías importadoras a comprar el último número que hubiera llegado del extraordinario incitador que era ese órgano de cultura. Fue a través de esa revista como empezaron a ser conocidos entre nosotros autores como Max Scheler, Edmundo Husserl, Nicolai Hartmann, Martín Heidegger, Jean Paul Sartre, Jorge Simmel, etc, principalmente los filósofos alemanes”. Naranjo Villegas, Abel: "La influencia española en la secularización de la filosofía en Colombia”, en Tendencias actuales de la filosofía en Colombia, Universidad Santo Tomás, Bogotá, 1988. p. 132,

119 "Scheler es quizás el filósofo más profundo y claro a la vez que ha tenido Europa a lo largo de su historia. Nadie tan denso como él. Nadie ha puesto al servicio de temas tan interesantes su conciencia filosófica". Carrillo, R. Escritos filosóficos, Universidad Santo Tomás, Bogotá, 1986. pp. 27- 28.

120 "Esta experiencia por el continente suramericano conduce a Antonio García a ser parte del grupo de pensadores latinoamericanos que buscó la elaboración de una teoría sociológica de Latinoamérica, independiente de los patrones de pensamiento europeos y norteamericanos.” Villamizar, J.C “Antonio García Nosa”. En Castro Gómez S., Flores Malagón, A, Hoyos, G y Millán de Benavides (Editores) Pensamiento colombiano del siglo xx. Bogotá, Instituto Pensar. Pontificia Universidad Javeriana. 2007 .p. 51. 
En los últimos años han aflorado casi todas las corrientes filosóficas que circulan en el mundo occidental, aunque por supuesto no todas con la misma intensidad. Evidentemente se ha ido formando un enriquecimiento notable que supera con creces el anterior período de relativo anquilosamiento durante las primeras décadas del presente siglo. Daniel Herrera Restrepo y Danilo Cruz Vélez se encargaron de difundir la fenomenología (Herrera, 1986), el existencialismo heideggeriano y el pensamiento de Nietzsche. Rafael Carrillo contribuyó notablemente a esa entrada en la "normalidad filosófica" (Salazar, 1986, p. 40). ${ }^{121}$ Los problemas del ser humano, la cultura y los valores han sido temas centrales de la reflexión filosófica colombiana de estas últimas décadas ${ }^{122} \mathrm{y}$ también, en alguna medida, las preocupaciones por los problemas de la filosofía de la ciencia y del lenguaje han encontrado serios estudiosos en Rubén Sierra Mejía (Sierra, 1978) y Magdalena de Holguín (Holguín, 1988, pp. 283-289) entre otros.

La corriente hermenéutica se abrió paso a fines del siglo xx a través de la labor de Jaime Rubio Angulo y Carlos Gutiérrez. De igual modo, la teoría crítica de la Escuela de Frankfurt y, en particular, las ideas de Marcuse y Habermas, han tenido una acogida favorable en prestigiosos intelectuales como Guillermo Hoyos (Hoyos, 1986) y Rubén Jaramillo Vélez.

La vida cultural en Colombia es muy rica a pesar de las dificultades socioeconómicas y la inestabilidad política del país en las últimas décadas. Numerosas instituciones culturales y universidades de prestigio internacional atestiguan también que la vida filosófica académica y extra académica goza de un merecido reconocimiento. Tanto en la Universidad Nacional como en la Universidad Javeriana, la Universidad de los Andes, la Universidad Santo

121 "Una de las características que definen el estado actual de la filosofía en Colombia es la existencia y convivencia de un conjunto de tendencias y corrientes. Se trata de un pluralismo jamás experimentado en la historia cultural del país. Ello puede ser quizá un signo inequívoco de que estamos entrando en nuestra mayoría de edad y de que la actividad filosófica se esté encaminando a su "normalización". Salazar Ramos, R. "Acerca de la filosofía latinoamericana en la última década en Colombia”, en Cuadernos de filosofía latinoamericana. Universidad Santo Tomás, Bogotá, julio-diciembre de 1986. no. 28-29, p. 40.

122 Una simple ojeada a la copiosa producción filosófica contenida en "La filosofía en Colombia. Bibliografía del siglo xx" lo testifican, Véase Cuadernos de Filosofía Latinoamericana, (22-23). Universidad Santo Tomás, Bogotá .enero-junio, 1985. 
Tomás, la Universidad del Rosario, la Universidad de San Buenaventura, la Universidad del Valle y la Universidad de Antioquía se destacan por la intensidad en la actividad filosófica que se plasma en eventos, publicaciones, maestrías, doctorados, entre otros.

Resultaría complejo adelantar las causas que han motivado la vitalización filosófica en Colombia, la cual ha estado acompañada por un relativo repliegue académico del pensamiento religioso, mucho más tolerante en la actualidad a las nuevas corrientes de la filosofía contemporánea, incluso ante el marxismo. Indudablemente la diversidad de contradicciones que caracteriza a la sociedad civil, así como la estructura político-económica de este país constituye elementos imprescindibles a considerar a la hora de efectuar cualquier análisis sobre las particularidades de la vida intelectual colombiana.

Colombia es un país capitalista dependiente (Silva Colmenares, 1983, p.143 $)^{123}$ con una estructura socioeconómica tan deformada por el fenómeno del subdesarrollo que sus élites de poder pueden darse el lujo de coquetear con formas propias del capitalismo monopolista de Estado, que se vinculan a amplias esferas de empresas transnacionales y a la oligarquía financiera internacional, y a la vez tiene que enfrentar las insuficiencias y deterioros propios de relaciones económicas precapitalistas en el campo que llegan, en algunas regiones, hasta los niveles que poseían las culturas precolombinas.

Su economía no se formó a partir de la extracción de minerales como en otros países de la región, sino básicamente en la explotación agrícola de algunos renglones básicos como el café y el banano. Siendo un país con recursos naturales muy ricos, ha enfrentado en las últimas décadas la contradicción de mantener un crecimiento económico sostenido, pero paradójicamente

123 "Solo la concepción marxista-leninista, dialéctica e histórica del capitalismo dependiente nos permite entender las características que el proceso de monopolización asume en un país atrasado como Colombia, y la aparente contradicción que existe entre dependencia y monopolización, no en el sentido de que la una excluye la otra -asimilada mecánicamente la monopolización a sinónimo de imperialismo-, sino en el de si es posible que en un país dependiente se desarrolle un proceso interno de monopolización, diferente aunque simultáneo del dominio imperialista que se impone desde fuera". Silva Colmenares, J. Tras la máscara del subdesarrollo: dependencia y monopolios, Carlos Valencia Editores, Bogotá, 1983. p 143. 
un acelerado ritmo de polarización de la riqueza que ha conducido a una agudización extrema de la violencia política y social, si bien en los últimos tiempos se avizora un posible relativo clima de paz.

Los gobiernos han ido heredando insolubles situaciones por esa cada vez más injusta forma de distribución de las riquezas que genera el capitalismo y mucho más en países dependientes. Se han visto incapacitados para evitar el incremento de la inseguridad que sufre prácticamente toda la población, pues de ella no pueden escapar ni los sectores más beneficiados económicamente.

La violencia que ha sacudido el país durante varias décadas en que la lucha guerrillera, las bandas paramilitares y el narcotráfico han constituido sus componentes más significativos, ha ido provocando una migración masiva hacia las ciudades y una deformación extraordinaria entre los sectores rural y urbano de la población, que se traduce en el incremento de los problemas sociales.

Desde el Bogotazo, Colombia ha vivido en estado de sitio y guerra civil y, por mucho que la reflexión filosófica más depurada o pretendidamente desideologizada (Guadarrama, 1990, p. 170) ${ }^{124}$ aspire a desarrollarse al margen de esta realidad, de un modo u otro siempre aflora algún síntoma de incertidumbre o de escepticismo en las distintas miradas escrutadoras del búho de Minerva, máxime cuando se considera la validez de la tesis de Jaime Rubio Angulo al sostener que "en Colombia los sistemas filosóficos - a lo que podríamos añadir que como en cualquier otra parte en distinto grado - han estado unidos atávicamente con los partidos políticos" (Rubio, 1982, p.49), lo cual no debe entenderse como una simplificadora reducción de la filosofía a la política o a las ideologías (Sánchez y Guadarrama, 1988, p. 108) sino sencillamente tomar en cuenta su adecuada conexión para poder comprender mejor el papel que tiene la filosofía en la conciencia social colombiana.

En correspondencia con el grado de concientación respecto a la realidad de ese país y de los pueblos latinoamericanos prendió durante los años setenta y ochenta en algunos círculos intelectuales, especialmente en la Universidad

124 "A esta tendencia en el filosofar latinoamericano la hemos denominado hermenéutica o exegética". Guadarrama González, P. Marxismo y antimarxismo en América Latina, Universidad INCCA de Colombia, Bogotá, 1990. p. 170. 
de Santo Tomás, el ideario de la filosofía de la liberación. ${ }^{125}$ Entre sus principales representantes se han destacado Germán Marquínez Argote, Roberto Salazar, Jaime Rubio Angulo, Luis José González Álvarez, Eudoro Rodríguez Albarracín, Joaquín Zabalza Iriarte, Juan José Sanz y otros. Su producción teórica durante la década de los años ochenta fue realmente significativa como lo atestiguan numerosas publicaciones.

A la hora de efectuar una valoración general de los filósofos colombianos de la liberación, como el presente trabajo - consciente de la necesidad de una investigación más amplia e independientemente del hecho que la mayoría de ellos se han distanciado de esta corriente filosófica- se aprecia que en su caso se pusieron de manifiesto muchas de las características que estuvieron presentes en seguidores de esta filosofía en otros países por aquella época.

Ante todo, se observaba cierto intento inicial por abandonar las formas tradicionales del filosofar por su procedencia europea, al considerarlas "ontologizantes" y justificadoras del status de donde han surgido. "Venimos acostumbrados desde la colonia a responder a las preguntas sobre el hombre en una forma genérica y abstracta. Sentimos la inquietud por conocer cuál es nuestra realidad concreta, como hombres y como pueblo. Pero no encontramos la respuesta a esa inquietud en los manuales de filosofía importados, ni tampoco en los escritos aquí" (Marquínez, 1990, p. IV.) escriben en una de sus obras más significativas como expresión autocrítica ante la filosofía académica tradicional. No por gusto tales planteamientos motivarían la irritación de quienes aún se mantienen en los planos del universalismo abstracto y menosprecian como seudofilosóficas tales preocupaciones de los filósofos de la liberación en su afán por aterrizar en la universalidad concreta.

Se propusieron la necesidad de elaborar una nueva forma de filosofar para América Latina, lo cual no significaría romper rotundamente con el pensamiento europeo, sino asimilarlo por su utilidad y validez, e incluso continuar desarrollando muchas de las categorías elaboradas en aquellas latitudes, pero que tenían validez universal. En realidad lo que han reclamado es la elaboración de una filosofía desde y para América Latina, pero que no

125 Solamente las publicaciones de la editorial de la Universidad de Santo Tomás de Bogotá y las editoriales Nueva América y El Búho en esos años son suficientes para demostrar esta tesis. 
se limite a este continente ni a la elaboración de formulaciones y categorías exclusivamente emergidas en este contexto.

El problema que se esconde detrás de esta filosofía circunstancial, históricamente ubicada, trasciende los límites de la búsqueda de una filosofía original. Ese no es el sentido verdadero de la búsqueda; lo que se busca es la identidad y autenticidad como latinoamericanos y lo que se rechaza en última instancia es el mimetismo europeizante que la distorsiona. Por eso critican con razón que "todo nuestro deseo de ser consiste en ser como el europeo: hablar como él, vestir como él, pensar como él y divertimos como él" (Marquínez, 1990, p.155), y por tal motivo reclaman: "Hemos de tomar conciencia de nuestro propio ser; hemos de definir nuestra identidad. Tenemos que luchar por ser auténticos. La opción por la alteridad es una opción por nuestra propia alteridad, dicho de otro modo, por la alteridad de nuestro propio ser frente al de los pueblos que nos han dominado por los siglos. Para ello hay que comenzar por tener fe en nosotros mismos" (Marquínez, 1990, p.155). De tal modo, insistían en la reivindicación de los valores contenidos en el hombre y la cultura latinoamericanos.

Tal vez sea este uno de los méritos principales de esta corriente de pensamiento. Con ese objetivo le plantearon a la filosofía nuevas tareas que usualmente en esos momentos no eran consideradas propiamente filosóficas. Pues en primer lugar la enseñanza tradicional de la historia de la filosofía ha partido por lo regular de una perspectiva eurocentrista, que incluso en ocasiones ha llegado a minimizar el pensamiento oriental. Sin embargo, desde que por la década de los años cuarenta se inició en América Latina el movimiento de estudio de historia de las ideas en esta región, que tuvo en Leopoldo Zea (Zea, 1957) uno de sus máximos exponentes, se ha ido formando un cierto viraje en algunas partes dirigido a la revalorización de la herencia filosófica nacional y continental (Zea, 1965).

Los simpatizantes, inicialmente con la filosofía de la liberación en Colombia, se destacaron en esa labor. Dieron a conocer estudios detallados sobre diversas etapas del pensamiento colombiano y han publicado las principales obras de sus mayores representantes, muchas de las cuales se encontraban relegadas en el olvido y eran desconocidas por las nuevas generaciones intelectuales.

Le han dedicado atención especial al tema de la identidad cultural latinoamericana y a la contextualidad del latinoamericano en su mundo, para desde ahí desarrollar la reflexión filosófica. Partieron del criterio de que 
"Latinoamérica es nuestro mundo" (Marquínez, 1986, p. 9) y desde esa óptica aspiran a cultivar la filosofía, en particular la metafísica (Marquínez, 1994).

No es menos cierto que resulta sugerente y válida la inquietud por situarse en la realidad latinoamericana para desde allí proyectarse hacia los sempiternos problemas filosóficos, como consciente o inconscientemente han hecho los pensadores de todas las épocas. Sin embargo, los propios filósofos de la liberación no lograron desembarazarse por completo del complejo de inferioridad que ha embargado durante tanto tiempo a muchos de los pensadores latinoamericanos respecto a la producción filosófica. De ahí que sostengan que "en creación, filosóficamente no merecemos aun el aprobado [...] lo que necesitamos son voces y no ecos" (Marquínez, 1986, p. 400). Idea esta que en cierto modo contradice esa labor arqueológica de rescate de la herencia filosófica vernácula. Sencillamente se sostuvieron tales criterios porque se siguió tomando como exclusiva vara de medir los indiscutibles logros de la producción filosófica europea. Pero la hiperbolización de su función paradigmática en ocasiones no tomaba en cuenta que el propio evaluador necesita ser evaluado, y que, aunque toda creación filosófica aspira por el propio contenido y esencia de la filosofía, a la formulación de ideas válidas para todas las épocas y circunstancias, dicha producción intelectual se realiza en una época y una circunstancia determinada y siempre llevará el sello de su momentaneidad trascendiendo en sus proyecciones universales.

La investigación por la identidad y el ser latinoamericanos ha conducido a los filósofos de la liberación en Colombia a profundizar la problemática antropológica desde diversos ángulos. No han subestimado ninguna de las perspectivas científicas desde las cuales se aborda el problema genético, evolutivo, histórico, sicológico, sociológico, entre otras, pero sus reflexiones por ser genuinamente filosóficas no se reducen a ninguna de estas ópticas. Han tratado de horadar en diversos componentes de la esencia humana para poder intentar rescatar al latinoamericano de su actual situación marginal. Para ello han partido de la premisa de que "el hombre es un ser inacabado e inconcluso, se va haciendo en la medida en que se humaniza y se proyecta. En consecuencia el hombre es un proyecto." (Marquínez, 1986, p. 39). También lo conciben como "un ser que hace cultura y que se hace gracias a la cultura" (Marquínez, 1986, p. 126). Precisamente lo que ha aspirado la filosofía de la liberación es que el latinoamericano se humanice y salgan de 
las condiciones infrahumanas en que viven las mayorías de estos pueblos. Para ese fin, se detienen en tales formulaciones que bien podrían parecer genéricas o abstractas, pero que en verdad no siempre lo son porque están inmersas en una contextualidad de propuestas mucho más concretas y apropiadas a las exigencias del hombrelatinoamericano.

En primer lugar, resultan muy definitorias sus críticas a las distintas formas de enajenación que se dan en la sociedad burguesa en general y en la colombiana en particular; sus claras alusiones a ese "pueblo subdesarrollado, dependiente y oprimido, con una gran parte de su población marginada, hundida en la miseria, carente de los recursos mínimos necesarios para llevar una vida humana" (Marquínez, 1990, p. 141) su franco reconocimiento de que esa sociedad es inmoral y que "se caracteriza por la opresión de la persona" (Marquínez, 1990, p.142) sus denuncias a la despiadada explotación capitalista, la corrupción administrativa, la prostitución, la mendicidad, pero sobre todo de la irresponsabilidad del sistema (1990, p.143), el acomodamiento de la élite económica y política, incluso de algunos miembros de la Iglesia, demuestran que sus reflexiones filosóficas se ubican en una terrenalidad que no puede ser del agrado de muchos de los llamados filósofos "puros" que las critican.

Al planteamiento de tales factores subhumanizados añaden la conclusión de la responsabilidad de cada persona con dicha situación, "La responsabilidad de cada uno es mayor o menor, según el grado de participación en la vida social" (Marquínez, 1990, p. 145) y por tanto consideran que todos pueden aportar a su modo para transformar ese medio tan hostil a la condición humana. Combaten el conformismo, la resignación (Marquínez, 1990, p. 146) y estimulan la toma de conciencia por la responsabilidad individual que a cada uno atañe.

Es precisamente en el plano de la concientización donde este movimiento filosófico tuvo mayores potencialidades movilizadoras, consciente de su capacidad y de sus límites, por eso sostenían:

En una u otra forma todos somos agentes de liberación o de opresión personal, social, política, no solo por nuestras acciones, sino también por nuestras omisiones. Para un filósofo honesto que no viva en las nubes de la ontología, sino en la realidad cotidiana, no le queda difícil ver claro y proyectar claridad sobre el quehacer libera- 
dor. Quizás las circunstancias y su compromiso liberador le obliguen en un momento a una praxis- práctica, a la acción; pero de suyo, en cuanto filósofo, lo que debe aportar al proceso de liberación es una praxis-teórica, es decir, generación de pensamiento capaz de iluminar el proceso. Aquí valdría lo de zapatero a tus zapatos. Es tan importante esta iluminación que sin ella cualquier déspota podría hacer cantar a sus esclavos himnos de libertad en un proceso seudoliberador (Colectivo de autores, 1986, pp. 304-305).

De tal modo queda definida la función de la filosofía de la liberación en su grado de compromiso con la transformación social. No cabe duda de lo meritoria que resulta esa labor iluminadora que puede y debe desempeñar la filosofía en cualquier circunstancia. El solo hecho de reconocer la necesidad de desempeñar esa misión impone al filósofo algún tipo de compromiso, aun cuando no llegue a su conversión en intelectual orgánico como sugería Gramsci. Pero la historia de la filosofía universal guarda entre sus páginas infinidad de pruebas para demostrar que ningún filósofo que deba ser considerado como tal plenamente ha podido desarrollar su actividad intelectual de espaldas al mundo sociopolítico que le ha tocado vivir y sin pronunciarse en favor o en contra de él. Y para hacerlo han tenido obligatoriamente que embadurnarse con el lodo de la actividad política para poder reflexionar sobre la sociedad con conocimiento profundo y vivencial de causas y no desde atalayas distantes que le obstaculizan la mirada por la bruma de otras mediaciones humanas, ni Platón, ni Aristóteles, ni Tomás de Aquino, ni Maquiavelo, ni Descartes, ni Hegel, ni Heidegger pudieron desentenderse del coyuntural medio político que les impuso definirse y actuar en correspondencia con sus definiciones.

Mucho menos han podido liberarse los filósofos de la liberación de la exigida definición política que ha sido común a la tradición filosófica latinoamericana y que, en ocasiones, ha provocado infundadas críticas por parte de los defensores de la neutralidad axiológica en la filosofía.

Si algo ha caracterizado este movimiento desde que tomó fuerza en la década de los años setenta en Argentina y México (Cerutti, 1983) fue su insatisfacción con la política tradicional de las élites gobernantes en la región, especialmente por su claudicación ante la penetración imperialista 
que ha desangrado a nuestros pueblos. ${ }^{126}$ Desde un principio se dieron a la tarea de buscar algunas poleas transmisoras de las ideas liberadoras que se propugnaban (Guadarrama, 1986, pp. 25-30) ${ }^{127}$ para que llegaran al sujeto principal de la liberación: el pueblo. Por tal motivo, resulta algo contraproducente que por una parte se reclame responsabilidad y toma de posiciones ante las condiciones subhumanas de existencia del ser latinoamericano de las cuales han sido responsables las políticas ejercidas por las oligarquías dominantes en la mayoría de estos países- y por otra se intente dirimir la cuestión crucial, evadiendo de cierto modo la opción política y diluyéndola en la esfera de la concientización ética personal. Al menos eso puede entenderse cuando se plantea:

Sentimos el deber de la personalización, de la perfección de nuestro ser personal. Pero sentimos también que esto no es posible mientras nuestro pueblo siga oprimido, por la explotación, la miseria y la incultura. Y, a la inversa, sentimos el deber de liberarnos. Pero no creemos en cualquier forma de liberación. No creemos en el odio o la violencia como medios de liberación. No nos interesa propugnar una liberación política que nos depare un simple cambio de sistema opresor. Nuestra preocupación no consiste en el poder político de los sistemas. Consiste más bien en el poder de las personas. Creemos que seremos libres en la medida en que cobremos conciencia - todos- de que somos personas, con una dignidad y una fuerza que nos subleva eficazmente contra cualquier forma de opresión (Marquínez, 1990, p.162).

Es muy comprensible que en una sociedad sacudida por tanta violencia se hayan enarbolado fácilmente los métodos usualmente reconocidos como violentos — dado que existen otros muy sutiles que aparentemente para

126 Este elemento es muy común a todos los representantes de la filosofía de la liberación desde sus primeros momentos y se han mantenido como un criterio delimitador significativo a la hora de determinar quiénes están vinculados a dicha corriente de pensamiento, entre otros factores.

127 En el XI Congreso Interamericano de filosofía, Guadalajara, México, 1985, formulamos al respecto algunas críticas a la filosofía de la liberación que, a nuestro juicio, han sido positivamente valoradas por algunos de sus principales representantes. Guadarrama, P. "Reflexiones sobre la filosofía de la liberación latinoamericana", en Prometeo, Revista Latinoamericana de Filosofía (6): Universidad de Guadalajara, mayo-agosto de 1986. pp. 25-30. 
algunos no son reconocidos como violentos, como permitir que un niño muera por una enfermedad curable o un adulto fuerte por inanición ante la mirada de miles de transeúntes-y también puede comprenderse que una ética de base cristiana no estimule los odios entre los seres humanos. Ambos criterios son explicables. Pero lo difícil de compartir es que no haya que atender "el poder político de los sistemas" cuando sabido es que, como expresión concentrada de la economía, la política marca siempre las rutas por donde se encauzan las determinaciones últimas de los aparatos de poder que mantienen o trastocan los sistemas sociales, donde la individualidad de la persona puede quedar aplastada si no encuentra los adecuados canales para su dignificación.

Tal posición puede justificar el quietismo político que evidentemente resultaría nefasto para la labor liberadora que se defiende y para lograr el objetivo de que "la política debe tender a reubicar el pueblo en el poder" (González Álvarez, 1986, p. 247) donde "tenga cabida la alteridad del pobre, del marginado, del oprimido" (González Álvarez, 1986, p. 247).

Aun cuando son frecuentes las declaraciones y las formulaciones teóricas que inducen de algún modo a asumir compromisos políticos y, en ese sentido, la labor concientizadora de este movimiento-donde llega su radio de acción, que no es estrecho por cuanto a través del sistema de enseñanza desescolarizada se irradia por todo el país e incluso lo trasciende, por cuanto su labor publicista es extraordinaria- su actividad en general se orienta básicamente en el plano académico y en él encuentra adecuada recepción.

En realidad la filosofía de la liberación se distanció deliberadamente del academicismo tradicional y ha aspirado a reorientar el rumbo y la función de la filosofía (Salazar, 1969, p. 46) (28 $^{128}$ ponerla al servicio de la transformación de la realidad latinoamericana.

128 "En la Universidad Santo Tomás, por ejemplo, es importante destacar los debates y "juicios" que se entablaran a los profesores con respecto al tipo de filosofía que se estaba enseñando. Si bien el curriculum se nutría de una neoescolástica abierta, el estudiantado exigía que los planes de estudio contemplasen un pensamiento más acorde con la realidad vivida en ese entonces por los pueblos latinoamericanos. En cierto sentido, este cuestionamiento fue muy significativo en tanto logró "desquiciar" la tranquila conciencia de los docentes y del contenido que enseñaban. Al vivir la crisis estudiantil y su cuestionamiento, muchos de los profesores entraron en 
Esto no significa que lleguen a reducir el objeto de la filosofía al ser latinoamericano o a admitirse la apertura de una nueva era mundial de la filosofía latinoamericana, como parecía desprenderse de algunos de los primeros trabajos de Dussel y sus discípulos más ortodoxos. Eudoro Rodríguez esclarece adecuadamente la cuestión al escribir que "rechazamos de plano una afirmación de la filosofía latinoamericana en términos puramente geográficos (el simple proceso de socialización, la existencia de una economía mundial, etcétera de por sí serían argumentos contundentes para negar dicha posibilidad) y la aceptamos en términos históricos: como resultante en último término de una toma de conciencia de la dependencia y por lo mismo de la necesidad de una búsqueda de libertad" (Rodríguez, 1981, p.149). Por tal motivo, nos parecen infundadas algunas de las críticas que desde las más diversas posiciones filosóficas, incluyendo la marxista, se han ejercido de manera absolutizante sobre esta corriente al considerarse que atentan contra la esencia universal de la filosofía.

En realidad no se realiza ningún atentado contra la naturaleza última de la filosofía cuando se le exige al filósofo mayor proyección circunstancial a sus reflexiones, pues en última instancia ellas pueden trascender a la universalidad de la cultura humana, precisamente por haberse correspondido con determinadas exigencias epistemológicas y axiológicas que afloran en un momento dado y no en otro. Por tanto, debe esta corriente gozar del disfrute de la consideración de la autenticidad.

Al concebir la filosofía como "superación de lo existente" (Rodríguez, 1981, p.39), inspirado en Zea y también en Dussel, inicialmente Rodríguez profundiza en el contenido de la autenticidad y llega a la conclusión de que esta "solo es posible mediante la superación práctica de lo existente a través de una forma específica de praxis" (1981, pp.184-185) dejando entrever la necesidad de superar el academicismo del filosofar tradicional.

Estos y otros planteamientos incluso son mucho más radicales por su formulación, como los de Luis González Álvarez cuando sostiene "Lo que importa es que tomemos conciencia de la necesidad de la fortaleza. Somos un pueblo habituado a la resignación. Ya es hora de ponernos en actitud de ataque. Ya es hora de perder el miedo multisecular al poderoso opresor, sea

la tarea del repensamiento de la función de la filosofía en el seno de nuestras sociedades". Salazar Ramos, R. p. 46. 
un individuo, una nación o una compañía multinacional," (Marquínez, 1990, p. 163) en ocasiones podrían ser interpretados como arengas orientadas hacia la consecución de una praxis más consecuente.

En realidad, bien puede haber surtido ese efecto en determinados sectores que reciben la influencia de estas ideas. Pero nunca en verdad podrán ser enjuiciadas como incendiarias o peligrosas para el orden establecido, pues aunque cumplen un papel denunciatorio de los males de esa sociedad - hecho este que es muy habitual hasta en la prensa periódica de los países latinoamericanos y no siempre esas críticas son provenientes de las izquierdas - no llegan a precisar definidamente el modelo de sociedad a que aspiran y mucho menos las vías más efectivas para alcanzarlas, que no sea a través del perfeccionamiento ético, al cual las élites de poder nunca han temido, tal vez por su probada ineficacia, si no van acompañadas de cambios socioeconómicos y políticos radicales.

Plantean admirables propuestas de perfeccionamiento de la sociedad que podrían implicar cuestionarse las bases mismas del capitalismo al plantear la necesidad de una "primacía del trabajo sobre el capital es decir de los derechos de los trabajadores sobre el capital” (Marquínez, 1990, pp. 184185) pero el contenido ambiguo que las anima da lugar a que la motivación profundamente humanista que contiene se vea tarada por la incapacidad de romper con las formulaciones reproductivas en última instancia de la propia sociedad burguesa.

Debe puntualizarse que en el caso de la filosofía de la liberación en Colombia el humanismo que está latente en todos sus representantes y que se plasma ante todo en una práctica pedagógica inspirada en el postulado de Freyre de que "el hombre se humaniza humanizando su mundo" (Sanz, 1985, p. 247), no puede ser enmarcado en el clásico plano dicotómico de humanismo proletario. En este caso, como en muchos otros, la realidad se rebela contra las categorías que pretenden apresarla, pues se está en presencia de un movimiento filosófico que aspira, y realmente en muchos momentos lo logra, emanciparse de las formulaciones abstractas propias del filosofar tradicional, aunque en otras ocasiones no escape de ellas. Así se aproximan a un humanismo concreto y práctico cuando sostienen el principio de que: 
La primacía absoluta es el hombre. Pero no del hombre abstracto; sino de nuestro hombre, del campesino de nuestro pueblo, del obrero inculto, del desocupado, del gamin, del creyente, del indio, el negro, el mulato y el mestizo, del costeño y el que vive en las apartadas veredas de la cordillera, del analfabeto, de la mujer cargada de hijos y la prostituta, del que se emborracha con cerveza o aguardiente en cuanto tiene unos pesitos en el bolsillo, del ratero, el traficante de contrabando y el burócrata 'serruchero'. Este es el hombre medio de nuestro pueblo, no tengamos vergüenza en reconocerlo. Ese es el otro hombre que vive con nosotros, codo a codo en la oficina o en la fábrica; el que a los ricos, a los acomodados, a los empresarios, a las niñas de la alta sociedad, a los hombres de la iglesia, a los intelectuales les crea problemas. Ese es 'el otro' hombre, hermano nuestro, el que muchos quisieran que no existiese, la sombra que nos da mala imagen ante el extranjero civilizado, honrado, puntual, cumplidor del deber, limpio, etcétera" (Marquínez, 1990, pp.197-198).

Indudablemente esta caracterización de la diversidad en que se nos revela el verdadero ser latinoamericano y no con el que operan la mayoría de los tratados de ética, filosofía, derecho, entre otros, en los predios universitarios latinoamericanos, constituye una aproximación epistemológica inestimable para una reflexión filosófica que se proyecte hacia la liberación del humano, pues es a ese ser de carne y hueso que allí se describe al que hay que liberar y no al idílico de los comerciales.

En ese sentido, la filosofía de la liberación toma distancia del humanismo abstracto tradicional, pero se le vuelve a aproximar cuando pretende encontrar las soluciones con los llamados a la toma de conciencia filantrópica (Marquínez, 1990, p. 162) en quienes contribuyen a su marginación y explotación.

Esta ambigüedad que desde una perspectiva ideológica pudiera considerarse como expresión de un humanismo pequeño-burgués es muy consustancial al tercerismo, que ante las opciones fundamentales capitalismo y socialismo ha impregnado a la mayor parte de los identificados con esta corriente de pensamiento. Explícitamente quedó plasmado en Germán Marquínez Argote (1994) cuando planteaba:

Frente a esta situación global, históricamente dada o cumplida, la filosofía de la liberación latinoamericana pretende dar una respuesta auténtica. No puede ser una filosofía que transite por los esquemas 
ideológicos modernos con los que la dominación ha justificado su proyecto de poderío y lucro. No puede ser una filosofía a la europea, a la americana o al dictado del Kremlin: sería pensar desde la dominación. Se trata de una filosofía nueva que piensa desde abajo, desde el dominado y oprimido, articulando su voz antes silenciosa o no oída (p.82).

Esta posición ha sido muy común durante todo el período en que la confrontación, antes de la caída del Muro de Berlin, parecía inclinarse en favor del socialismo. Pero todo se modificó a tenor con el derrumbe de los países de Europa oriental y los altibajos de la perestroika que condujeron a la destrucción de la Unión Soviética (Guadarrama,1993a). Pero lo medular ha consistido en pronunciarse o no en favor de una sociedad más humana y, por tanto, alejada de las formas brutales de explotación y marginación capitalista.

Se ha dicho que son frecuentes y marcadas las críticas a ese tipo de sociedad por parte de los identificados con la filosofía de la liberación en ese país andino por su abierta identificación con los sectores más humildes de la población. Pero sería erróneo plantear que llegan a identificarse con el ideario socialista, entendiendo por este, en lo esencial, el predominio de los medios fundamentales de producción en forma social, estatal o colectiva.

Su aspiración principal es que se logre una mejor distribución de la riqueza social y que funcionen mecanismos más humanos en la producción y los servicios, sin que ello implique la eliminación de la propiedad privada sobre aquellos medios. Un capitalismo de rostro más humano es en última instancia la paradójica propuesta que plantea la filosofía de la liberación.

Por supuesto que sería absolutamente erróneo considerar este movimiento, en el caso colombiano, como algo homogéneo en este plano y en otros. Al igual que en el resto de los países, la diversidad de formaciones intelectuales y de posiciones en definitiva ante múltiples cuestiones básicas inherentes a la actividad filosófica los hace diferenciables. Pero aun así, ha sido una nota más común la identidad que la diferencia en este grupo si se compara con la situación de aquellos.

La identificación de la mayoría de este grupo de la Universidad de Santo Tomás, en Bogotá, se aprecia en los múltiples proyectos que han emprendido y fructificado de manera conjunta en cuanto a publicaciones, maestrías, doctorados, congresos, entre otros. Incluso se han esforzado por precisar la 
tonalidad que adquieren algunas categorías filosóficas en el ámbito latinoamericano y para ese fin elaboraron un Diccionario de filosofía con autores y temas latinoamericanos, en el que se señala que "somos conscientes de que frente a la gran tradición filosófica europea, la nuestra es por múltiples razones ciertamente pobre. Pero es nuestra y por ello nos interesa; no podemos darle la espalda, como tampoco podemos romper el cordón umbilical que nos liga a Europa y que nos sigue y seguirá nutriendo" (Colectivo de autores, 1986, p. 5). A la vez insisten en la necesidad de profundizar los estudios, con razón, de la simbólica latinoamericana. En este último sentido se destacan los trabajos de Jaime Rubio Angulo por su proyección hermenéutica y Germán Marquínez Argote con sus obras Macondo somos todos y Metafísica desde Latinoamérica, entre otras.

En la mayoría de estos autores, dada su vinculación a una universidad confesional, el aparato categorial que utilizan y muchas de las concepciones que sostienen están condicionados por tal situación, aunque en ocasiones no resulte fácil percibirlo. Se manifiestan algunos intentos de repensar la filosofía de la liberación a través de otras categorías del pensamiento europeo contemporáneo, como en Marquínez Argote, quien trata de entroncar esa filosofía con las del filósofo español Xavier Zubiri, de quien fue discípulo (Marquínez, 1987, pp. 125-137), Daniel Herrera Restrepo con la fenomenología y Luis José González Álvarez con el personalismo de Mounier. Esto significa que se mantienen apegados a su formación filosófica inicial y a la vez tratan de utilizarla en función del nuevo proyecto emprendido con la filosofía de la liberación, rescatando así los "granos racionales" que está contenidos en aquellas otras tradiciones.

Esto explica que se manifiesten matices muy diferentes entre los distintos autores, por las distintas tradiciones filosóficas anteriormente apropiadas, pero como han tratado de poner esas ideas al servicio del nuevo objetivo, los puntos de coincidencia entre sus respectivos lenguajes son abundantes.

Un rasgo muy positivo de la actividad intelectual de este grupo de filósofos ha sido su intento, a nuestro juicio logrado, de clarificar los canales de comunicación con sus interlocutores principales, con sus lectores, con los estudiantes, como intermediarios principales con el sujeto de la liberación: el pueblo. Han sabido esquivar el esoterismo que en ocasiones fue frecuente en ciertos discursos esotéricos de la liberación concebidos al parecer solo para iniciados. Sin afectar el rigor académico, más bien por el 
contrario, manteniendo un decoroso nivel y rigor teórico han sabido formular las ideas básicas del discurso filosófico de la liberación en un lenguaje apropiado y con un didactismo refinado. Este hecho ha favorecido la difusión que han tenido sus ideas más allá de los círculos intelectuales tradicionales. A la vez han tratado de encontrar en la sabiduría popular $-y$ en ese sentido se evidencia la influencia del grupo argentino de la filosofía inculturada, como Kusch, Scannonne, Cullen, Picotti, y otros- elementos nutritivos que enriquezcan la renovada, realista y sobre todo socialmente ubicada concepción del mundo que propugnan.

En los sistemáticos congresos internacionales de filosofía latinoamericana que se celebraron en aquellos años setenta y ochenta fue apreciable la acogida democrática que ofrecieron a las más diversas posiciones filosóficas, pero sobre todo a aquellos trabajos que contribuyen al enriquecimiento de los valores culturales latinoamericanos. Levantaron estandartes de lucha contra la penetración cultural de las potencias capitalistas y sus hábitos de sociedad de consumo y antepusieron a estos mecanismos neutralizadores de la cultura vernácula los monumentos del mundo cultural latinoamericano, la riqueza de su sincretismo racial, religioso y folklórico.

Partiendo de la premisa de que "el sujeto propio de la cultura es el pueblo" (Marquínez, 1990, p. 315) y que "toda cultura tiene carácter de universalidad" (Marquínez, 1990, p. 316) proponían que "lo nuevo que tenemos que decir está en lo popular y en lo aborigen, y buscar esos campos no implica buscar algo distinto a uno mismo, algo superado o arcaico. Se trata de algo que es una cara importante de uno mismo y que a su vez podría generar algo nuevo. En consecuencia preguntar por lo popular es preguntar por lo propio" (Marquínez, 1990, p. 317).

Tal identificación con esas expresiones de la cultura popular indudablemente contribuyeron a enriquecer la sensibilidad de los intelectuales en una nueva percepción axiológica de lo, hasta el presente, peyorativamente denominado cultura popular. En ese y otros aspectos de revalidación de la cultura y la historia nacional y popular de los distintos países latinoamericanos, en la búsqueda conformadora de su identidad, ha contribuido también, entre otras corrientes intelectuales de la región, este de la filosofía de la liberación.

Toda la labor reivindicadora de la cultura latinoamericana y concientizada de la necesidad de emprender una transformación de las condiciones 
de existencia del ser humano emparentan a la filosofía de la liberación con la teología de la liberación y con el marxismo, a pesar de las críticas a algunas de sus interpretaciones ortodoxas, una veces fundadas y otras no tanto, que contra este último también afloran en los trabajos de dichos filósofos.

En relación con la teología de la liberación, es lógico presuponer que en un país, cuna de Camilo Torres y de la conferencia de Medellín, donde la conciencia religiosa juega un papel decisivo en todos los órdenes de la vida intelectual, los vínculos con la filosofía de la liberación sean significativos. Aun así, es imprescindible señalar que los respectivos radios de acción de estas dos corrientes de pensamiento están bien delimitados, aunque se superpongan en algunos sectores de la población como algunos sectores estudiantiles o del magisterio, donde ambos han tenido alguna influencia.

Es cierto que no falta ocasión para que los filósofos de la liberación en Colombia combinen sus más agudas reflexiones teóricas con algún que otro postulado de fe. Pero de ahí a aceptar que se trata exclusivamente de una nueva modalidad de la filosofía religiosa contemporánea en su integridad, como algunos críticos de este movimiento sostienen, hay una gran distancia, por cuanto el objeto principal de sus análisis filosóficos no es Dios, ni siquiera la relación del ser humano con él, sino el humano mismo en su circunstancialidad enajenada por múltiples mecanismos y los problemas que plantea su liberación. Eso no significa que dejen de dedicar extensos tratados a los problemas filosóficos de la religión, o que en trabajos dedicados a cuestiones epistemológicas o éticas no emerjan sus declaratorias de fe cristiana, pero en ningún modo constituye este tema el eje central de sus preocupaciones en este plano, aunque muy bien puede serlo en otro.

De lo que se trata por lo regular en la discusión filosófica es de buscar todas las vías posibles que contribuyan a la desalienación humana y, con ese fin, llegan a reconocer hasta la validez circunstancial de la tesis atribuida erróneamente de Marx sobre la religión como opio de los pueblos cuando se utiliza como instrumento de dominación ideológica de la Iglesia para justificar una situación injusta (Marquínez, 1986, p. 55). Tanto este hecho como las innegables coincidencias con algunas de las tesis fundamentales de la concepción materialista de la historia, unido al factor de constituir el marxismo, así como los temas sobre democracia y derechos humanos (Guadarrama, 2016 y 2016a), referentes obligados en la vida intelectual latinoamericana del siglo $\mathrm{xx}$, les ha 
llevado a definir posiciones ante esta filosofía y ante las diferentes praxis políticas que han pretendido inspirarse en sus principios.

En su gran mayoría, los seguidores de la filosofía de la liberación en Colombia, como en otras partes, han reconocido en determinadas interpretaciones del marxismo suficiente rigor y validez en la explicación de determinados fenómenos sociales. Como bien observa Eudoro Rodríguez en relación con el marxismo "no se trata por tanto de una moda, sino de un fenómeno histórico cultural que tiene actualmente una incidencia profunda y determinante en la dinámica y en la estructuración de nuestro mundo, en las opciones fundamentales de nuestra vida y en el destino y el futuro del hombre" (Rodríguez, 1985, p. 19). Incluso en el plano epistemológico y metodológico se manifiestan coincidencias con algunos postulados de la concepción dialéctico-materialista del mundo al admitir la validez de determinadas leyes, categorías y principios de la dialéctica, independientemente del hecho de que se presenten las desavenencias lógicas cuando se aborda la cuestión gnoseológico-ontológica fundamental y también en algunas derivaciones de actitud ante la praxis política que demanda una consecuente posición marxista ante la historia. Pero aun así, por lo regular esto no constituye un obstáculo insalvable para determinar los puntos de confluencia entre ambas posturas filosóficas.

Sin embargo, tampoco han escapado en algunas ocasiones a las tergiversaciones o deformaciones teratológicas que hacen del marxismo muchos de sus acérrimos enemigos que en lugar de contribuir al esclarecimiento de los posibles puntos de confluencia han sembrado la semilla de la bifurcación.

Por lo general ha prevalecido una visión aprobatoria del humanismo práctico ${ }^{129}$ contenido en el marxismo y esgrimida como arma fundamental de la Revolución Cubana (Rodríguez, 1985, p. 130). También, reivindicando

129 Por humanismo práctico - término utilizado por Marx en sus trabajos tempranos como La sagrada familia y los Manuscritos económicos y filosóficos de 1844 así como los de humanismo concreto, humanismo positivo y humanismo culto que diferenciaba del humanismo real de Feuerbach-, entendemos una postura de compromiso activo, militante y arriesgado con la defensa de la dignidad de determinados grupos humanos, que se diferencia del humanismo abstracto que se limita a simples declaraciones filantrópicas, que no trascienden más allá de cierta misericordia o postura piadosa ante indígenas, esclavos, siervos, proletarios, mujeres, niños, minusválidos, etc. Un humanismo práctico debe distanciarse del antropocentrismo que ha caracterizado generalmente a la cultura occiden- 
el sentido liberador de esta filosofía, Eudoro Rodríguez plantea acertadamente que "en el pensamiento de Marx la relación dialéctica entre el hombre y la naturaleza permite a este una cierta autonomía y originalidad, de modo tal que los problemas de la liberación, de la vida y de la muerte vuelven a colocarse en el centro de sus preocupaciones" (Marquínez, 1990, pp. 272-274), distanciándose significativamente de los análisis infundiosos que desconocen el verdadero lugar y papel que le otorgó Marx al ser humano como productor de sus circunstancias.

Por su parte, Marquínez Argote se ha encargado también de criticar el pretendido economicismo que se le ha endilgado injustamente al marxismo (Marquínez, 1990, p. 42). Tales aproximaciones de la filosofía de la liberación con el marxismo llevaron en algunos casos a atacar a la primera como un instrumento sutil y una nueva táctica del movimiento comunismo internacional (González, 1988, p. 4), ${ }^{130}$ de la misma forma que la teología de la liberación ha sido así considerada por la plataforma de Santa Fe II, cuando realmente en el espíritu de muchos de los iniciadores de dicha corriente filosófica de la liberación prendía la intención de constituirse en una verdadera alternativa ante el marxismo anquilosado en algunos sectores de la vida intelectual y política latinoamericana y mundial.

tal y tomar en consideración la imprescindible interdependencia entre el hombre y la naturaleza. Véase: Guadarrama "Humanismo y marxismo". Marx Vive. IV. Universidad Nacional de Colombia. Bogotá. 2006. pp. 209-226; Marx y el marxismo crítico en el siglo XXI. Colectivo de autores. Camilo Valqui Cachi y Cutberto Pastor Bazán. (Coordinadores). Ediciones EON-Universidad Autónoma de Guerrero. México. DF. 2011. pp. 313-332. Disponible en: http://es.scribd.com/doc/90507863/ Cmilo-v-C-El-Marxismo-Critico

130 "Se ha insistido en calificar de comunista o marxista al movimiento latinoamericano liberador y a todos cuantos participamos en él, con el fin de desprestigiarlo y poderlo combatir como una amenaza del sistema comunista contra los países 'democráticos' del sistema capitalista. Aunque la teoría marxista de la alienación y de la lucha de clases ha jugado un papel clave en la conformación de este movimiento, de ningún modo se puede sostener que en sí mismo sea marxista y, mucho menos, que esté al servicio del comunismo. Esta no es sino una campaña orquestada por el capitalismo internacional y cierto conservadurismo eclesiástico, que sienten perder el poder político, económico y religioso del pueblo latinoamericano". González Álvarez L. J. "Equidad y justicia en el marco de la filosofía de la liberación", ponencia presentada al II Encuentro Nacional de Investigadores en Recursos Humanos y Desarrollo, Universidad de Santo Tomás, Bogotá. 1988 p. 4. (inédita). 
Realmente, tanto la actitud ante el marxismo como doctrina filosófica, como el tercerismo político entre el capitalismo y el comunismo (González, 1988 , p. 4) ${ }^{131}$ han tenido su razón de ser en la filosofía de la liberación. En primer lugar, este es un movimiento que no ha emergido de las izquierdas tradicionales, sino de intelectuales honestos comprometidos con los sufrimientos de los pueblos latinoamericanos y, por tanto, motivados por encontrar alternativas diferentes de las propuestas usuales que no podían ver en el llamado "socialismo real" una salida favorable, como los hechos se encargaron de testificar con el derrumbe de estos modelos y, a tenor con ese estado de cosas que se pretendía implantar en nombre del comunismo, muy distante de la propia visión de Marx y Engels (1996) al respecto (p.36), ${ }^{132}$ había ocurrido un relativo estancamiento en la producción teórica de filiación marxista en algunos países, y mucho más en los que se encargaban solamente de reproducir lo allí elaborado que atentaba contra la eficiencia crítico-dialéctica, componente fundamental del núcleo duro del marxismo (Guadarrama, 1998, pp. 249-250). ${ }^{133}$

En el ámbito latinoamericano, el pensamiento y la praxis marxista no pueden de ningún modo ser concebidas como estancadas, pues hay suficientes

131 "En realidad, la mayoría de los grupos liberacionistas están tan alejados de los intereses del comunismo como de los del capitalismo. Buscan romper definitivamente con la dominación de cualquier potencia extranjera y de las oligarquías nacionales, con el único interés de que el pueblo se organice con autonomía en el desarrollo de su proyecto colectivo de vida, que es el bien común”. Ibídem.

132 "Para nosotros, el comunismo no es un estado que debe implantarse, un ideal al que haya de sujetarse la realidad. Nosotros llamamos comunismo al movimiento real que anula y supera, el estado de cosas actual. Las condiciones de este movimiento se desprenden de las premisas actualmente existentes". Marx, C. y F. Engels: $L a$ ideología alemana, Editora Revolucionaria, La Habana, 1966. p. 36.

133 "Ya en ocasión anterior pretendimos precisar también algunos de los elementos componentes esenciales del posible "núcleo duro" del marxismo al indicar "el carácter científico de sus explicaciones acerca de las leyes fundamentales que rigen el desarrollo de la historia y en especial de la sociedad capitalista. El esclarecimiento de los factores que intervienen en el proceso de producción de la conciencia humana, el lugar de la práctica en la teoría del conocimiento, el despliegue de las leyes objetivas que rigen las formaciones económico-sociales, en especial, la dialéctica de la correlación entre las fuerzas productivas y las relaciones de producción; la adecuada significación de la determinación de los elementos de carácter económico en su correlación con la divergente y dinámica acción de las formas de la conciencia social: el papel impulsor de la lucha de clases, conducente a través de la revolu- 
muestras de originalidad y autenticidad en la proyección del ideario marxista desde Mariátegui (Guadarrama, 1998, pp. 206-219) hasta el Che Guevara (Guadarrama, 205, pp. 40-47) y Fidel Castro, por solo nombrar a los más descollantes, pero que van acompañados de una larga lista que hoy son objeto de investigación y reivindicación por muchos investigadores del tema (Sheldon, 1984). Pero también habría que señalar que el dogmatismo, el sectarismo, la importación de esquemas, entre otros, eran elementos frecuentes en muchos movimientos y partidos de orientación marxista. Si a eso se une la funesta campaña anticomunista que ha inundado la conciencia social latinoamericana en el siglo xx, el resultado no puede ser otro que el proclamado rechazo a todo lo que huela a marxismo y mucho más marxismo-leninismo, que podía ser combinado con el maoísmo, trotskysmo, senderismo, y demás, en el ámbito político latinoamericano. Incluso este fenómeno se ha presentado hasta en aquellos que desde las filas de la filosofía de la liberación han demostrado por su producción teórica y la evolución de su pensamiento, que han mantenido y consolidado mayores puntos de confluencias que desavenencias con el marxismo, por su humanismo científico, como es el caso de Enrique Dussel, entre otros.

La situación de los que en Colombia abrazaron la filosofía de la liberación y la cultivaron depuradamente hasta cosechar una obra digna de los mejores reconocimientos no escapaba a esas problemáticas respecto a la justipreciación del marxismo y, por tal motivo, han desplegado una honesta labor crítica frente a los descalabros de muchas de las ideas que se lanzan

ción social hacia una sociedad que emprende la eliminación de los antagonismos de clases; los mecanismos de enajenación que reproduce la sociedad capitalista con el básico objetivo de la mayor obtención de plusvalía, constituye en algunos de los principales componentes de lo que podría considerarse el núcleo duro de la teoría marxista, atendiendo a su trascendencia y validez universalmente reconocida.

Por supuesto que dentro de cada uno de esos elementos es posible e imprescindible delimitar un sinnúmero de ideas que, a su vez, desempeñan un papel fundamental que si no están presentes, hay razones suficientes para dudar del posible carácter marxista de lo que se plantea o al menos, de sus puntos de coincidencia fundamentales con las tesis esenciales de aquel Prometeo de Tréveris" Guadarrama, P. "El núcleo duro de la teoría marxista y su afectación por la crisis del socialismo", En América Latina, marxismo y postmodernidad. Universidad INCCA de Colombia. Bogotá. 1994 pp. 204-205; Humanismo, marxismo y postmodernidad. Editorial Ciencias Sociales. La Habana. 1998. pp. 249-250. 
invocando esta doctrina y de reconocimiento a las potencialidades epistemológicas y humanistas de dicha teoría.

El espíritu prometeico que animó Marx y a quienes han continuado dignamente su obra, los instrumentos desalienadores que han desarrollado y las firmes convicciones en el perfeccionamiento humano a través de medios más efectivos que los usualmente concebidos por el pensamiento ilustrado, han dado lugar a que muchos de los filósofos de la liberación cambien sus gafas para mirar el marxismo, especialmente en los momentos actuales, por las transformaciones que ya tiene este movimiento a escala continental con la creciente decantación de posiciones ante las contradicciones fundamentales de nuestra época, como la evidenció el congreso de filosofía latinoamericana de Ciudad Juárez, México, en mayo de 1990, en el que se reunieron los principales representantes de la filosofía y de la teología de la liberación.

A la vez, muchos marxistas han cambiado sus gafas al apreciarla por conocer mejor las particularidades de esta corriente filosófica latinoamericana (Vargas, 1990, p. 100), ${ }^{134}$ de igual modo que se incrementó el diálogo entre estos y la teología de la liberación, cuando respectivamente se han estudiado con profundidad. Tal vez sea este uno de los resultados que más ha aspirado alcanzar en su trabajo investigativo el grupo de pensamiento filosófico latinoamericano de la Universidad Central "Marta Abreu" de Las Villas, en Santa Clara, Cuba, donde se han realizado varios trabajos de investigación, tesis doctorales, cursos y congresos dedicados al estudio de la filosofía de la liberación.

Si el objetivo fundamental de todos los que en estas tierras aspiran a dignificar el ser humano desde diversas perspectivas filosóficas es contribuir por diversas vías a la reflexión y a la concientización necesarias para lograr la necesaria liberación nacional y social de los pueblos latinoamericanos, es deber de la investigación histórica de las ideas revelar todos los granos

134 Entre esos análisis se destaca el de Gabriel Vargas Lozano, quien considera no sin razón "que no debe hablarse de filosofía de la liberación sino de filosofías", lo cual exige una necesaria diferenciación en cada caso. Vargas Lozano, G.: ¿Qué hacer con la filosofía en América Latina?, México. Universidad Autónoma Metropolitana. 1998 p. 100. 
racionales que están contenidos tanto en esta como en otras corrientes filosóficas existentes en la región.

Un fenómeno interesante se ha originado en los últimos años en el seno de estas distintas corrientes. Algunos de sus representantes se han desprendido de las usuales consideraciones peyorativas respecto a la filosofía de la liberación, y expresan actualmente sus simpatías por el proyecto que las motiva, como es el caso de Francisco Miró Quesada en Perú y otras personalidades de la filosofía en América Latina. Tal actitud no constituye un simple reconocimiento diplomático, sino admitir al menos la posibilidad real de elaborar creaciones filosóficas que trasciendan en un futuro por sus aportes a la cultura occidental y mundial, al considerarse que "la práctica filosófica ha logrado entre nosotros un estadio de madurez, podríamos decir de mayoría de edad, en el maneje de las cuestiones filosóficas" (Sierra, 1987, p. 124). Aun cuando no se admita propiamente la existencia de una filosofía latinoamericana. Es ese un paso de avance notable en el proceso constructivo no de nuevas racionalidades como simple juego intelectual que satisfaga la curiosidad de neófitos, sino de nuevos planteamientos dentro de nuestra racionalidad que ya ha dado suficientes pruebas de su vigor, validez y capacidad regenerativa

La filosofía de la liberación ha tenido el mérito de hurgar mucho más que otras tendencias filosóficas en los más recónditos rincones de las enajenadas condiciones de vida del hombre contemporáneo, lógicamente desde una perspectiva latinoamericana, como otras pueden haberse planteado problemas similares desde otras perspectivas. Pero al igual que en tales casos, la validez de sus descubrimientos ha trascendido fronteras geográficas; la filosofía de la liberación ha formulado ideas asimilables en muchas latitudes a la par que enjuiciables

El hecho de haber tratado de incursionar en la búsqueda de diferentes vías para alcanzar la liberación del ser humano en sus tres niveles fundamentales "promoción política, promoción social y promoción cultural"(Marquínez, 1990, p. 335) por medio de las reflexiones pedagógica, ética, estética, religiosa, jurídica, antropológica, sexológica, sociológica y político-económica, constituye una muestra de la integralidad sistémica que le han impregnado a sus investigaciones Este hecho de por sí no le otorga obligado prestigio académico, pues muchas son las investigaciones desde otras posiciones filosóficas y sobre otros temas que también así lo hacen. La cuestión medular 
consiste en el tratamiento analítico, pormenorizado y a la vez integrado a un cuerpo conceptual muy bien estructurado y definido que le evita digresiones.

Sería exagerado aseverar que en cada una de estas esferas donde han incursionado para apuntalar una teoría de la liberación humana hayan aportado ideas nuevas. La mayoría de las veces las retoman de la rica tradición filosófica occidental de la cual no reniegan, pero el sentido en que se formulan las ideas adquiere nuevas connotaciones y sugiere nuevos cuestionamientos que no estaban contenidos en las formulaciones originales porque responden a nuevas demandas y se proyectan desde una diferente óptica. Detenido examen merecería este aspecto que no puede ser emprendido en un análisis tan generalizador como el presente. De seguro ese estudio llegaría entre algunas de sus conclusiones al criterio de que este grupo de filósofos, aunque no llegó a resolver los problemas objeto de análisis para lograr la liberación humana, ha tenido el mérito, al menos, de haberlo planteado de forma original y auténtica.

La historia universal de la filosofía contiene innumerables ejemplos en los que se muestra cómo el saber humano ha ido escalando infinitamente a partir no solo de aseveraciones paradigmáticas, sino de cuestionamientos que ponen en crisis las aceptadas y que la mayoría de las veces no han sido resueltas por sus generadores. El tiempo dirá la última palabra a las futuras generaciones de investigadores de la vida filosófica latinoamericana respecto a la trascendencia o intrascendencia de esta corriente filosófica, que al menos no podrán ignorar.

Es cierto que la liberación del ser humano de todas las fuerzas enajenantes ha sido una aspiración de todo saber filosófico respetable. Sin embargo, no siempre los resultados se han correspondido con las intenciones y los grados de autenticidad se han visto sacudidos por la formulación en ocasiones de ideas mucho más enajenantes que las que se han pretendido superar. De ahí que el problema sobre qué debe ser considerado herencia espiritual y filosófica genuina no está resuelto. ¿Es asimilable y cultivable todo lo generado por las cabezas filosóficas de todas las épocas y latitudes? A ese cuestionamiento no se le puede ofrecer rápida e irreflexiva respuesta por las nefastas consecuencias que puede acarrear una asunción indiscriminada.

De igual modo, no es adecuado reaccionar ante el heterogéneo movimiento intelectual que constituye la filosofía de la liberación en América Latina y habrá en cada país, como en Colombia, y en cada representante, 
que ir a la búsqueda de su differentia specifica, lo cual no excluye que pueden efectuarse valoraciones generalizadoras como las que aquí se han intentado y que permiten llegar a la conclusión de que se trata en este caso de una corriente de pensamiento profundamente humanista, reivindicadora de la cultura y de la filosofía en América Latina sin pretensiones segregacionistas o hegemonistas, sino simplemente reclamantes de su justipreciación, progresista por sus acertadas críticas a las diversas formas de enajenación que genera la sociedad capitalista; escrutadora de una opción sociopolítica más justa y democrática para hombre latinoamericano aunque no implique la opción por el socialismo.

La filosofía de la liberación, en lugar de entorpecer la propagación de las ideas marxistas y revolucionarias, como algunos críticos de izquierda han podido llegar a pensar, puede ser considerada un vehículo muy apropiado en el ámbito latinoamericano, y colombiano en especial, donde el catolicismo posee dimensiones colosales en el dominio de la conciencia popular, para propiciar el enjuiciamiento crítico de la sociedad actual y superar el quietismo y el conformismo que han estimulado las ideologías justificatorias del presente status quo. Sus seguidores, de igual modo que no deben ser vistos como un nuevo ardid del comunismo internacional, tampoco pueden ser considerados como nuevos adversarios en el combate filosófico e ideológico, sino como compañeros de lucha de aquellos que desde otras tradiciones de pensamiento, y por tanto con instrumental categoríal y concepciones diferentes, combaten también por la humanización del latinoamericano en circunstancias diferentes. 
Capítulo IX

BIBLIOTECA

(INE COLOMBIANA 
